Check for updates

Cite this: RSC Adv., 2017, 7, 28918

Received 7th May 2017

Accepted 26th May 2017

DOI: 10.1039/c7ra05151d

rsc.li/rsc-advances

\section{Fabricating an anionic polyacrylamide (APAM) with an anionic block structure for high turbidity water separation and purification $\uparrow$}

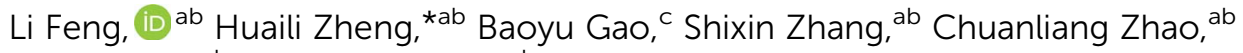 \\ Yuhao Zhou ${ }^{\mathrm{ab}}$ and Bincheng Xu $\mathrm{Xb}^{\mathrm{ab}}$
}

\begin{abstract}
Ultraviolet (UV)-initiated template polymerization (UTP) was used as a feasible strategy to prepare a novel anionic polyacrylamide (APAM) with a microblock structure. In the template copolymerization system, acrylamide (AM) and sodium allylsulfonate (SAS) were used as monomers, and poly (allylammonium chloride) (PAAC) as a template. The chemical properties of the polymers were observed by Fourier transform infrared spectroscopy (FT-IR), scanning electron microscope (SEM), ${ }^{1} \mathrm{H}\left({ }^{13} \mathrm{C}\right)$ nuclear magnetic resonance spectroscopy $\left({ }^{1} \mathrm{H}\left({ }^{13} \mathrm{C}\right)\right)$, and thermogravimetry/differential scanning calorimetry (TG/DSC). Results showed that the novel anionic microblock structure was formed in the template copolymer. Besides, the results of the association constant $\left(K_{M}\right)$ indicated that the copolymerization followed I Zipup (ZIP) template polymerization mechanism, which indicated the formation of the microblock structure again. Parameters such as $\mathrm{pH}$ and dosage that affected the flocculation performance, flocculation kinetics and the FTIR spectra of the generated flocs were investigated to further observe the effect of anionic microblocks on flocculation performance and understand the relationship between the flocs and flocculants. Flocculation experimental results demonstrated that the anionic microblocks in the template copolymer could enhance the charge neutralization and bridging ability, and therefore an excellent flocculation performance of treating high turbidity water was observed.
\end{abstract}

\section{Introduction}

The increasing establishment of mining and processing plants, smelting plants and coking factories have contributed much to the national economic and societal development. ${ }^{1-3}$ However, the industry waste water generated by these plants severely destroys and pollutes the natural water environment and further threatens human health, since this industry waste water is infamous for high turbidity caused by high levels of suspended solids (SS). ${ }^{4-6}$ The task of separating suspended solids becomes more and more challenging and hard because these suspended solids are always negatively/positively charged and these colloidal particles suspend stably in the water. ${ }^{7}$ According to statistics, the turbidity of the waste water has reached 10000 NTU in some cases in China. ${ }^{8}$ Therefore, it becomes an

${ }^{a}$ Key Laboratory of the Three Gorges Reservoir Region's Eco-Environment, Ministry of Education, Chongqing University, Chongqing 400045, China.E-mail: zhl6512@126. com; Fax: +8623 65120827; Tel: +862365120827

${ }^{b}$ National Centre for International Research of Low-carbon and Green Buildings, Chongqing University, Chongqing 400045, China

${ }^{c}$ Shandong Key Laboratory of Water Pollution Control and Resource Reuse, School of Environmental Science and Engineering, Shandong University, Jinan 250100, China

$\uparrow$ Electronic supplementary information (ESI) available. See DOI: 10.1039/c7ra05151d important issue for environment engineers to separate and remove these suspended solids form waste water efficiently.

In the process of waste water treatment, flocculation is regarded as an important purification technique and has been widely applied due to its prominent advantages such as high efficiency, low cost and simple operation compared with other purification techniques. ${ }^{\mathbf{9}, \mathbf{1 0}}$ As a common and widely used flocculant, the synthetic polyelectrolyte, especially the anionic polyacrylamide (APAM) has got more and more attention in waste water treatment because its excellent solid-water separation performance. On one hand, the particles with opposite charge can be thoroughly neutralized and destablized by the anionic chemical group. ${ }^{11,12}$ On the other hand, these destabilized particles will be captured by the molecule chain of APAM to agglomerate and form large and compact flocs, and thus flocculation occurs. ${ }^{13}$ During the solid-water separation process, the main mechanisms involved are charge neutralization, bridging and electrostatic patching, which have been demonstrated by many previous studies. ${ }^{14,15}$ Up to now, a series of anionic polyacrylamide with high flocculation performance have been developed and applied in the waste water treatment. ${ }^{16,17}$ However, the defect of the APAM, namely, the disordered and random distribution of anionic units in the polymer chain, seriously restricts the further enhancement of the solidwater separation ability. In addition to the molecular weight 
(MW) and the density of the anionic monomer, the configuration and the distribution of anionic units also affect the final flocculation performance. ${ }^{18}$ If the anionic units orderly distributes in the polymer chain of APAM to form the anionic microblock structure, the negative charge of the anionic group becomes more centralized and will neutralize the positive charged particles completely, thus increasing the charge neutralization ability. ${ }^{19}$ Meanwhile, the strong repulsive force between anionic microblocks are advantageous for the stretch and extension of the polymer chain, and therefore the bridging ability of the polymer is improved.$^{20}$ Now, the most critical issue is to search for a new approach to prepare the novel APAM with microblock structure, whereas it is incapable for traditional synthesis methods.

Fortunately, the appearance of template polymerization technology which has been used to synthesize nanowire and nanopore arrays, nanostructures, medical drugs and et al. will provide a new way in the study of synthesizing the anionic polymer. ${ }^{21-24}$ In order to acquire the novel microblock structures in the anionic polymer chain, the template with a controllable length will work as a matrix to arrange and assemble the anionic monomers. In this study, poly (allylammonium chloride) (PAAC) was chosen as template because PAAC with positive charge not only adsorbs and arranges the anionic monomers on its polymer chain to form pre-microblock structures under electrostatic attraction, but also has a property of easy separation from the copolymer system. ${ }^{25}$ Furthermore, ultraviolet (UV)-initiated polymerization can be employed to prepare the copolymer because of its relative advantages such as high efficiency, low cost and environment-friendly. ${ }^{26}$ Therefore, UVinitiated template polymerization (UTP) was used to synthesize the flocculant with a microblock structure in the polymer chain, and the possible route for prepare the template copolymer is shown in Fig. 1. Acrylamide (AM) and sodium allylsulfonate (SAS) were categorized as the safe and cheap monomers which have been widely used in the preparation of flocculants. ${ }^{27,28}$ Meanwhile, the previous researches have manifested that AM and SAS were harmless and eco-friendly, and therefore AM and SAS were selected to prepare template copolymer (TPAS) through UPT and it has prospective applications in water treatment in future. ${ }^{29,30}$ This new way for preparation of a new anionic copolymer with a microblock structure will be meaningful and significant in polymer synthesis and application.

Considering all aforementioned factors, this study attempts to (1) synthesize the template copolymer (TPAS) with the anionic microblock structure through UTP using AM and SAS as monomers, and PAAC as template; (2) elaborate the template polymerization mechanism through the analysis of the association constant $K_{\mathrm{M}}$; (3) characterize the chemical structure of polymers using FT-IR, scanning electron microscope (SEM), ${ }^{1} \mathrm{H}$ $\left({ }^{13} \mathrm{C}\right)$ NMR and TGA; (4) investigate the flocculation kinetic of the flocculants and the influence of the $\mathrm{pH}$ and dosage on the flocculation performance; and (5) summarize the flocculation mechanism through the investigation of zeta potentials and the FTIR spectra of the formed flocs.

\section{Materials and methods}

\subsection{Materials}

The monomer AM and SAS were purchased from Chongqing Lanjie Tap Water Company (Chongqing, China). Urea $\left[\mathrm{CO}\left(\mathrm{NH}_{2}\right)_{2}\right]$ and initiator 2,2'-azobis[2-(2-imidazolin-2-yl) propane]dihydrochloride (VA-044) were sourced from Apotheker Chemical Reagent Co., Ltd. (Chendou, China). Besides, template poly (allylammonium chloride) (PAAC) was obtained from Shandong Xintai Water Treatment (Zaozhuang, China), and its molecular weight (MW) was 4200. The above reagents were of analytical grade except for AM and SAS (technical grade). The hematite powder $(\mathrm{Fe} \geq 91 \%, 100$ mesh size) was purchased from Lingshou jiashuo building materials processing Co., Ltd. (Lingshou, China).

Commercial flocculants APAM-1 [copolymerization of AM and sodium methylacrylsulfonate (SAMS)] and APAM-2 [copolymerization of AM and 2-acrylamide-2-methylpro panesulfonic acid (AMPS)] were used for comparison in flocculation test, and their intrinsic viscosities were all of $7.8 \mathrm{dL} \mathrm{g}^{-1}$.

\subsection{Preparation of copolymers}

The experimental setup of UV-initiated template copolymerization was shown in Fig. 2, and the preparation procedures for template copolymer TPAS were as follows: $70 \mathrm{mmol}$ of AM, $30 \mathrm{mmol}$ of SAS, $0.241 \mathrm{mmol}$ of urea, $30 \mathrm{mmol}$ of PAAC $\left(n_{\mathrm{PAAC}}: n_{\mathrm{AA}}=1: 1\right)$ and $0.774 \mathrm{~mol}$ of deionized water were dissolved in a $100 \mathrm{~mL}$ glass vessel with a seal cover, followed by the adjustment of $\mathrm{pH}$ to the set value by $0.5 \mathrm{~mol} \mathrm{~L}^{-1} \mathrm{HCl}$ and $\mathrm{NaOH}$., the solution was bubbled through nitrogen for $30 \mathrm{~min}$ to remove oxygen and sealed immediately after addition of initiator VA-044 $(0.045 \mathrm{mmol})$. Subsequently, the mixture was exposed under the ultraviolet wave radiation generated by a UV lamp (wavelength: $365 \mathrm{~nm}$; power: $80 \mathrm{~W}$ ) for $70 \mathrm{~min}$ at room temperature to finish copolymerization. At last, the solid product was purified by acetone and dried in a vacuum oven at $95{ }^{\circ} \mathrm{C}$ for $24 \mathrm{~h}$. Besides, the non-template copolymer APAS was prepared in the absence of template, and the remaining

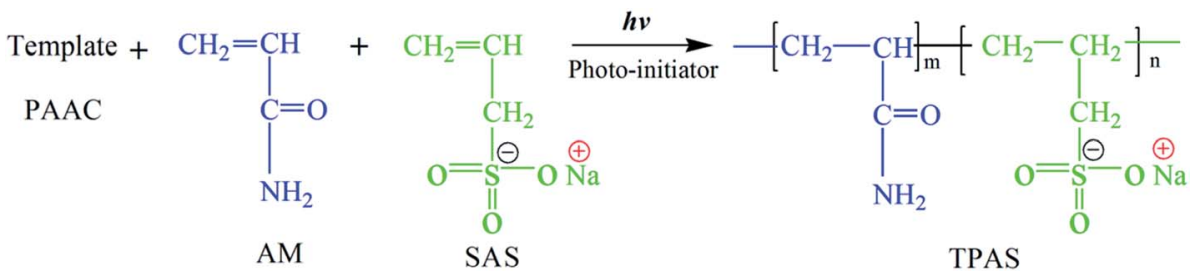

Fig. 1 The possible route for UV-initiated template copolymerization TPAS. 


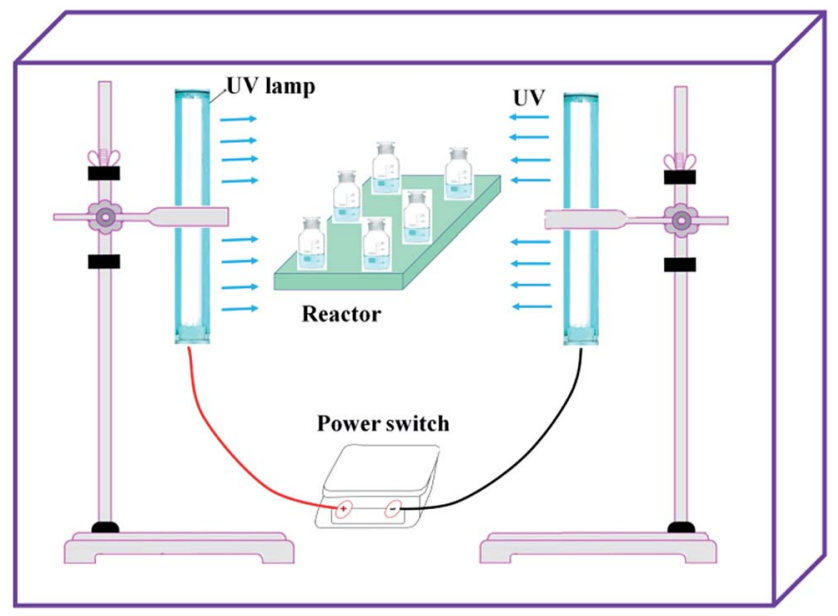

Fig. 2 The experimental setup of UV-initiated template copolymerization.

parameters and synthetic procedures were same as those of TPAS.

\subsection{Characteristics of copolymers}

The intrinsic viscosities of polymers $(\eta)$ used to assess the absorption and bridging ability was conducted on an Ubbelohde viscosity meter (Shanghai Shenyi Glass Instrumental Co. Ltd., China) in a $2 \mathrm{~mol} \mathrm{~L}^{-1}$ aqueous $\mathrm{NaCl}$ solution at $30{ }^{\circ} \mathrm{C},{ }^{13}$ and the molecular weight of the polymer was calculated by huggins equation displayed in ESI Text S1. $\dagger$ Moreover, the FT-IR was performed on a 550 Series II infrared spectrometer (Mettler Toledo Instruments Co., Ltd., Switzerland) to record the polymer function groups. ${ }^{1} \mathrm{H}\left({ }^{13} \mathrm{C}\right) \mathrm{NMR}$ of the products were recorded by an Avance 500 nuclear magnetic resonance spectrometer (Bruker Company, Ettlingen, Germany) in deuterium oxide $\left(\mathrm{D}_{2} \mathrm{O}\right)$. SEM analysis was performed on MIRA 3 LMU SEM system (TES-CAN Company, Czech Republic) to observe the morphologies of the copolymers. Besides, TGA and differential scanning calorimetry (DSC) of the polymers were conducted on a DTG-60H synchronal thermal analyzer (Shimadzu, Kyoto, Japan) at a heating rate of $10^{\circ} \mathrm{C} \mathrm{min}^{-1}$ under argon atmosphere from 20 to $600{ }^{\circ} \mathrm{C}$.

\subsection{Determination of $K_{M}$}

The type and mechanism of the template polymerization could be determined and revealed through the investigation of the association constant $\left(K_{\mathrm{M}}\right)$ between SAS and PAAC according to the previous researche. ${ }^{31}$ The $K_{\mathrm{M}}$ was examined using bag filter method, and its core part was a dialysis bag (Intercepted, $\mathrm{M}_{\mathrm{W}} \mathrm{CO}$ 10000 , MD 25, USA).$^{19}$ The operational approach of the bag filter method was described as follows. The dialysis bag with a given dose of template PAAC $\left(M_{\mathrm{W}}, 10000\right)$ was soaked in deionized water for dialysis. After $24 \mathrm{~h}$ dialysis, the molecular weight of PAAC in the dialysis bag would become similar because the low molecular weight PAAC $(<10000)$ would be removed during the process of dialysis. The precipitation of the intercepted PAAC occurred when a certain amount of acetone was added in the dialysis bag, and the precipitation was dried in a vacuum oven at $60{ }^{\circ} \mathrm{C}$ for $24 \mathrm{~h}$. After that, a given dose of SAS and PAAC precipitation were added into a glass beaker with $100 \mathrm{~mL}$ deionized water $(\mathrm{pH}=6)$. Subsequently, the glass beaker was sealed and kept for $24 \mathrm{~h}$ at room temperature to arrive a penetration balance. At last, the $K_{\mathrm{M}}$ was obtained through the eqn (1):

$$
K_{\mathrm{M}}=\frac{\left[\mathrm{PAAC}^{* * * * \mathrm{SAS}}\right]}{[\mathrm{PAAC}]_{\mathrm{f}}[\mathrm{SAS}]_{\mathrm{f}}}
$$

where $\left[\mathrm{PAAC}^{* * * *} \mathrm{AA}\right]$ referred to the concentration of the association of PAAC and SAS, $[\mathrm{PAAC}]_{\mathrm{f}}$ and $[\mathrm{SAS}]_{\mathrm{f}}$ referred to the free concentration at the dialysis balance. Besides, the conductometric titration method was used for determining the free concentration of PAAC and SAS.

\subsection{Flocculation test}

In this part, the flocculation efficiency of the template copolymers TPAS and non template copolymer APAS were evaluated by the treatment of simulated industry high turbidity water. Meantime, commercial flocculants (APAM-1, APAM-2) were used to make a comparison with TPAS and APAS. The simulated industry high turbidity water was prepared as follows. $3 \mathrm{~g}$ hematite powders were added in $1000 \mathrm{~mL}$ glass beaker with $1000 \mathrm{~mL}$ deionized water, and then stirred at $300 \mathrm{rpm} \cdot$ per min for $20 \mathrm{~min}$. Finally, the above liquid mixture was thoroughly dispersed under ultrasonic radiation for $10 \mathrm{~min}$. In order to make the controlled trial become more credible and persuasive, the flocculants used in this flocculation test were all of same intrinsic viscosity and anionic monomer content, and the details of these flocculants were described in Table 1 . The flocculation tests were performed on a program-controlled Jartest apparatus (ZR4-6, Zhongrun Water Industry Technology Development Co. Ltd., China) at ambient temperature. The $\mathrm{pH}$ of these simulated high turbidity water $(1000 \mathrm{~mL})$ was adjusted to the given value by $\mathrm{HCl}\left(0.5 \mathrm{~mol} \mathrm{~L}^{-1}\right)$ and $\mathrm{NaOH}\left(0.5 \mathrm{~mol} \mathrm{~L}^{-1}\right)$ after adding them into a $1000 \mathrm{~mL}$ glass beaker. The flocculation tests contained three procedures, and they were a rapid stirring at $200 \mathrm{rpm}$ for $1 \mathrm{~min}$, a slow stirring at $40 \mathrm{rpm}$ for $15 \mathrm{~min}$ and a setting period of $15 \mathrm{~min}$ without disturbance. ${ }^{32}$ After these procedures, the turbidity was examined by a $2100 \mathrm{P}$ turbidity meter (HACH, Loveland, $\mathrm{CO}$ ) and the zeta potential of supernatant collect from $2 \mathrm{~cm}$ below the water surface was recorded on a Zetasizer Nano ZS90 (Malvern Instruments Ltd., Malvern, UK). Flocculation behaviors of the polymers were evaluated in terms of turbidity removal rate (TR), flocs size, zeta potential and flocculation kinetic. Flocs size was investigated by a laser diffraction instrument (Mastersizer 2000, Malvern, U.K.). Each results was an average of three repeated test and the standard interval was controlled less than $5 \%$.

\section{Results and discussion}

\subsection{Characterization of flocculants}

3.1.1 FTIR spectra analysis. The FT-IR spectra of PAM, APAS and TPAS were presented in Fig. 3, and these flocculants 
Table 1 The details of flocculants used in the characterization and flocculation tests

\begin{tabular}{|c|c|c|c|c|}
\hline Flocculants $^{a}$ & $\begin{array}{l}\text { Anionic monomer } \\
\text { molar content }(\%)\end{array}$ & $\begin{array}{l}\text { Intrinsic viscosity } \\
\left(\mathrm{dL} \mathrm{g}^{-1}\right)\end{array}$ & $\begin{array}{l}\text { Conversion } \\
\text { rate }(\%)\end{array}$ & $\begin{array}{l}\text { Synthetic } \\
\text { method }\end{array}$ \\
\hline TPAS & 30.0 & 7.89 & 99.6 & UTP \\
\hline PAM & - & 7.85 & 99.8 & N-UTP \\
\hline APAM-1 & 30.0 & 7.85 & - & - \\
\hline APAM-2 & 30.0 & 7.85 & - & - \\
\hline
\end{tabular}

${ }^{a}$ TPAS: copolymer of SAS and AM by UV-initiated template copolymerization (UTP); APAS: copolymer of SAS and AM by non UV-initiated template copolymerization (N-UTP); PAM: homopolymer of AM by N-UTP; APAM-1: commercial copolymer of SAMS and AM; APAM-2: commercial copolymer of AMPS and AM.

had several similar adsorption peaks as follows. The strong stretching vibration of $-\mathrm{NH}_{2}$ and $\mathrm{C}=\mathrm{O}$ adsorption peaks were observed at $3443 \mathrm{~cm}^{-1}$ and $1666 \mathrm{~cm}^{-1}$, respectively. ${ }^{31}$ The asymmetric stretching vibration at $2943 \mathrm{~cm}^{-1}$ and $2844 \mathrm{~cm}^{-1}$ were caused by $-\mathrm{CH}_{3}$ and for $-\mathrm{CH}_{2}$ groups, respectively. ${ }^{19}$ The peak at $1453 \mathrm{~cm}^{-1}$ resulted from the deformation stretching vibration of methylene group. Compared with PAM, the characteristic absorption peaks of APAS and TPAS were shown at $1180 \mathrm{~cm}^{-1}$ and $1045 \mathrm{~cm}^{-1}$, which resulted from the sulfo group in the monomer SAS. ${ }^{33}$ Based the above analysis results, it revealed that the APAS and TPAS were successfully copolymerized by AM and SAS. Moreover, the FT-IR spectra of APAS and TPAS were very similar besides some slight shift in the peak area, which indicated that TPAS have the same functional group structures as APAS.

3.1.2 TG/DSC analysis. The TG/DSC analyses of the polymers were depicted in Fig. 4, where APAS and TPAS displayed three stages of the thermal decomposition. Due to the evaporation of the adsorbed moisture in the polymer, the first stage was observed in the range of $30-190{ }^{\circ} \mathrm{C}$ with a weight loss of 9.9 wt\% was for APAS and $7.9 \mathrm{wt} \%$ for TPAS. ${ }^{18}$ During the second stage occurred in the range of $190-330{ }^{\circ} \mathrm{C}$, a $22.4 \mathrm{wt} \%$ and 25.8 $\mathrm{wt} \%$ of weight loss were assigned to APAS and TPAS, respectively. According to the previous research, this stage weight loss

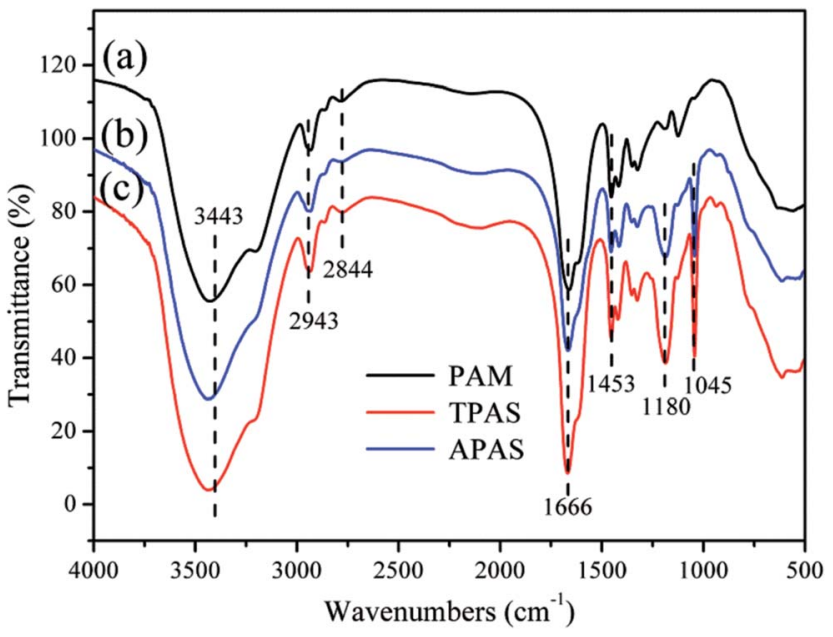

Fig. 3 FT-IR spectra of (a) PAM (b) APAS and (c) TPAS. was ascribed to the imine thermal decomposition in the amide group. ${ }^{26,34}$ The third stage was within the range of $330-510{ }^{\circ} \mathrm{C}$, and the weight loss was $51.6 \mathrm{wt} \%$ for APAS and $48.3 \mathrm{wt} \%$ for TPAS, which was contributed to the carbonization of the copolymer chain and the thermal decomposition of $-\mathrm{SO}_{3}-$ chemical group. ${ }^{13}$ Based on the above TG-DSC analytical results, it manifested that both TPAS and APAS showed inferior thermal stabilities. It was worth noting that double hump-like adsorption peaks ( 401.9 and $423.2^{\circ} \mathrm{C}$ ) in the DSC curve of TPAS but only one $\left(403.5{ }^{\circ} \mathrm{C}\right)$ in that of APAS were observed. This interesting phenomenon was related to the microblock structure generated in the template copolymer TPAS. Because of the order distribution and arrangement of the anionic monomers in the TPAS molecular chain, two evident blocky segments (SAS and AM segments) were formed and resulted in two characteristic absorption peaks. ${ }^{19,35}$ Nevertheless, the random distribution of monomers SAS and AM in the APAS molecular chain severely hindered the formation of the blocky fragments, and thus just a single adsorption peak was observed.

3.1.3 ${ }^{1} \mathbf{H}$ NMR spectra analysis. In Fig. 5, the ${ }^{1} \mathrm{H}$ NMR spectra of the PAM, APAS and TPAS were investigated to further understand their microstructure. As displayed in Fig. 5(a), the absorption peaks at $\delta=1.66 \mathrm{ppm}$ and $\delta=2.23 \mathrm{ppm}$ were derived from the $-\mathrm{CH}_{2}-$ (a) and - $\mathrm{CH}-(\mathrm{b})$ groups of AM monomer in PAM, respectively. ${ }^{36}$ After the addition of SAS monomer, the protons absorption peaks of $-\mathrm{CH}_{2}-$ (a) and - $\mathrm{CH}-$ (b) groups in both APAS and TPAS were all shown at the same chemical shift with PAM. Besides, the characteristic protons absorption peak at $\delta=2.89 \mathrm{ppm}$ (c) of $-\mathrm{CH}_{2} \mathrm{SO}_{3}$ - group in SAS was observed in both APAS and TPAS, which indicated that the copolymerization of AM and SAS successfully occurred. ${ }^{33}$ However, several subtle differences between APAS and TPAS should not be neglected. Compared with TPAS, seven extra peaks marked with different shape symbols at $\delta=1.05 \mathrm{ppm}, \delta=1.27 \mathrm{ppm}, \delta=$ $1.39 \mathrm{ppm}, \delta=1.91 \mathrm{ppm}, \delta=2.68, \delta=5.37$, and $\delta=5.91 \mathrm{ppm}$ arose in the ${ }^{1} \mathrm{H}$ NMR spectra of APAS. The difference between APAS and TPAS was related to their stereochemistry properties. Due to the formation of anionic microblocks in TPAS, the protons chemical environment of $-\mathrm{CH}_{2}-,-\mathrm{CH}-$ and $-\mathrm{CH}_{2} \mathrm{SO}_{3}-$ groups became more identical and only one resonance peak was observed for each group in principle. ${ }^{18}$ Nevertheless, the identical chemical environment was broken by the random 

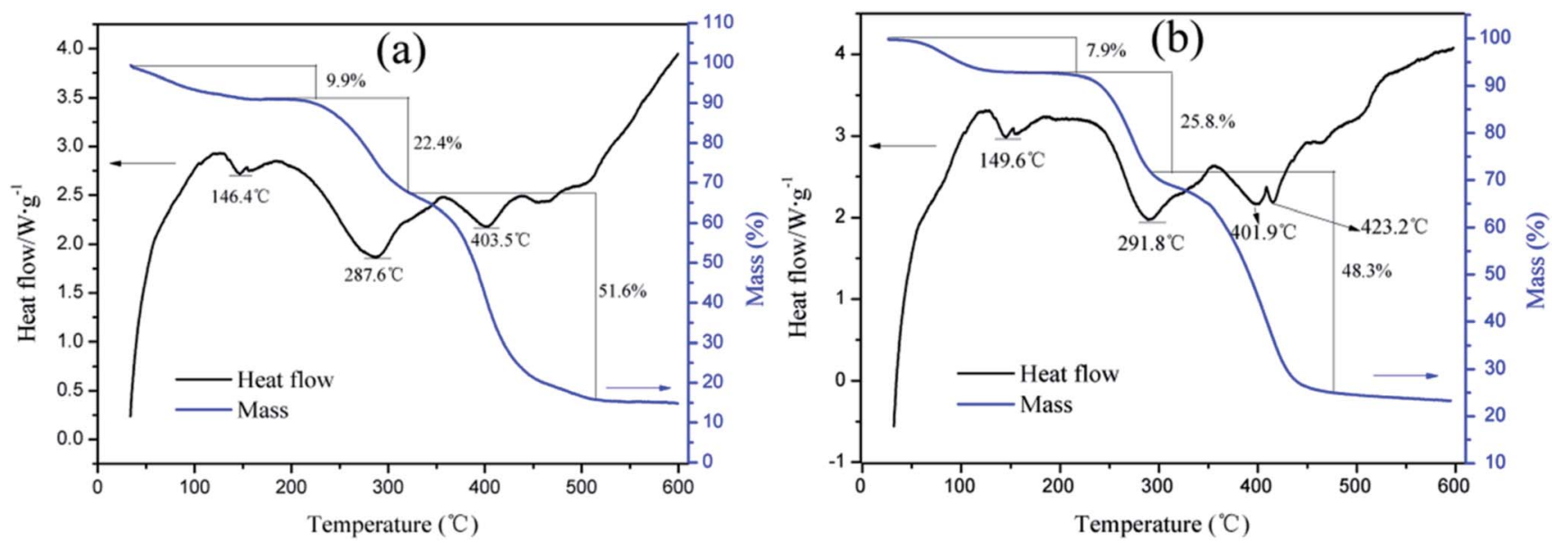

Fig. 4 Thermogravimetric curves of (a) APAS and (b) TPAS.

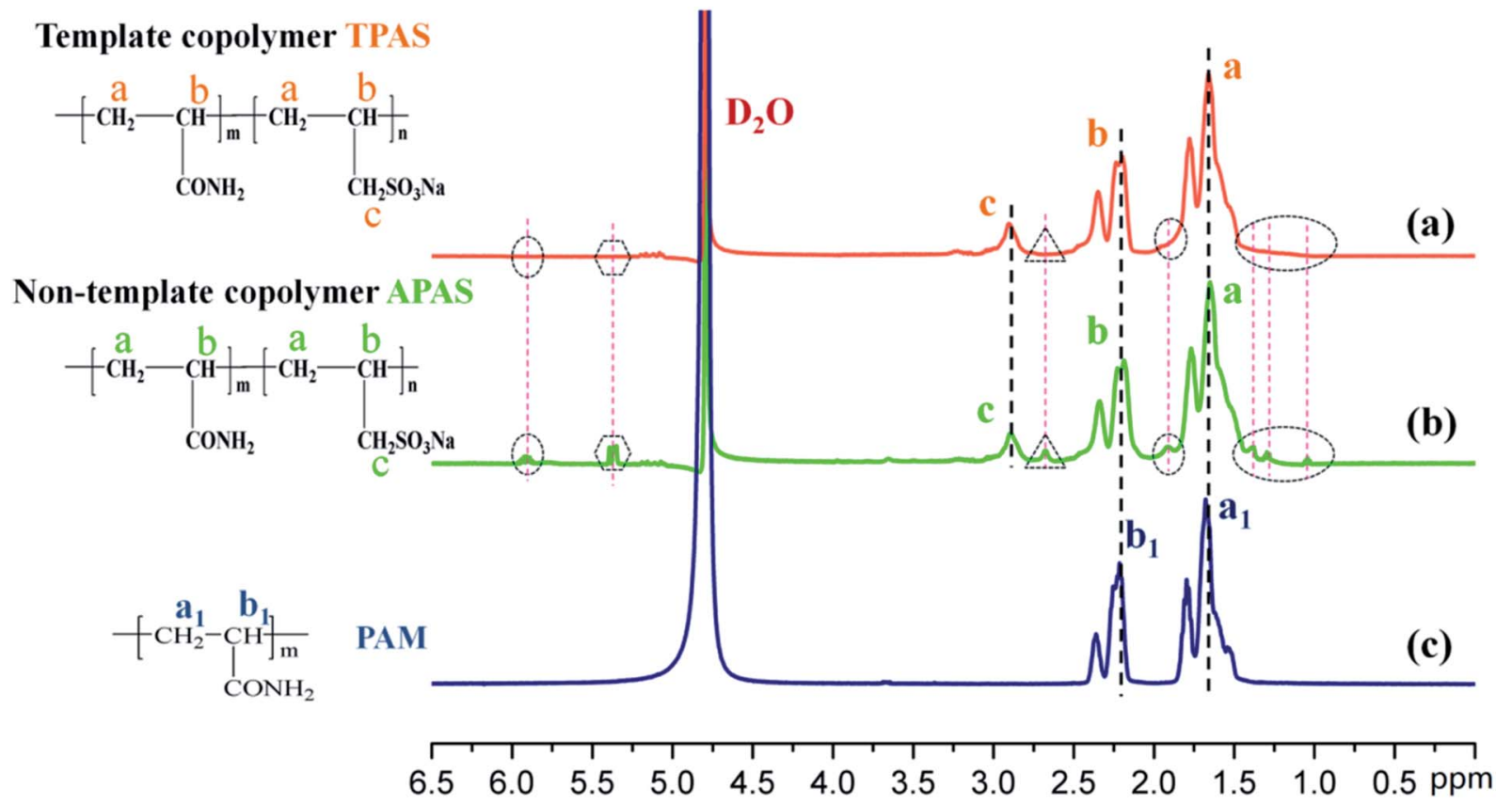

Fig. $5{ }^{1} \mathrm{H}$ NMR spectra of (a) TPAS, (a) APAS and (c) PAM.

distribution of anionic monomer (SAS) in APAS, and thus the different chemical environment resulted in individual split protons peaks with weak intensity for each group. Similar finding in the template copolymerization was reported by the previous research..$^{31,33}$ Based on the above analyses, it could be concluded that the anionic microblock structure was successfully prepared in TPAS.

3.1.4 ${ }^{13} \mathrm{C}$ NMR spectra analysis. As shown in Fig. 6 , the ${ }^{13} \mathrm{C}$ NMR spectra of the polymers were examined. The resonance peak observed at $34.72 \mathrm{ppm}$ in PAM was attributed to the backbone $-\mathrm{CH}_{2}-$ (a) group. ${ }^{31}$ The peak at $42.08 \mathrm{ppm}$ in PAM was derived from the backbone $-\mathrm{CH}-(\mathrm{b})$ group. ${ }^{19}$ Meanwhile, except for the similar resonance peaks with PAM, the characteristic resonance peaks of the $-\mathrm{CH}_{2} \mathrm{SO}_{3}-$ (d) chemical group in both TPAS and APAS were all manifested at $56.14 \mathrm{ppm}$, which further indicated that TPAS and APAS were copolymerized by AM and SAS. Because of the addition of template and employment of ultraviolet technology, the anionic microblocks was successfully formed in the polymer chain of TPAS. According to the previous study, the proportion of the anionic microblock sequence could be calculated from the number and relative intensity of the carbonyl carbon resonance peaks by using the MestReNova software. ${ }^{19,35,37}$ The calculated results were displayed in Table 2 in which the peaks of e, $f$ and $g$ represented SAS, AAS and AAA trials, respectively, and those trials were all central around AM. In Table 2, it was more apparent that the proportion of the AAA trial increased rapidly form $37.3 \%$ in APAS to $49.7 \%$ in TPAS. By contrast, the proportion of AAS and SAS trials decreased from $58.3 \%$ and $4.4 \%$ in APAS to $45.2 \%$ and $4.1 \%$ in TPAS, respectively. Due to the anionic microblocks formed in TPAS, these 
Template copolymer TPAS<smiles>CC(C)(C)[GeH2]C([GeH2])[GeH3]</smiles>

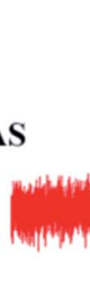
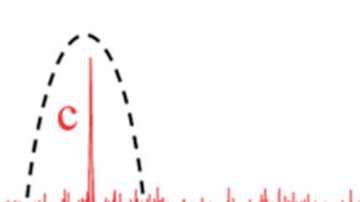

b

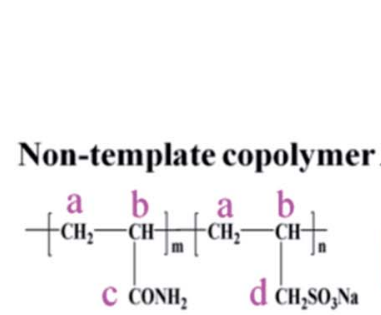

$+\underset{\mathrm{C}}{\mathrm{C}} \stackrel{\mathrm{C} \mathrm{NH}_{2}}{\underset{\mathrm{C}}{\mathrm{C}}+\frac{\mathrm{b}}{\mathrm{m}_{\mathrm{m}}}}$ PAM

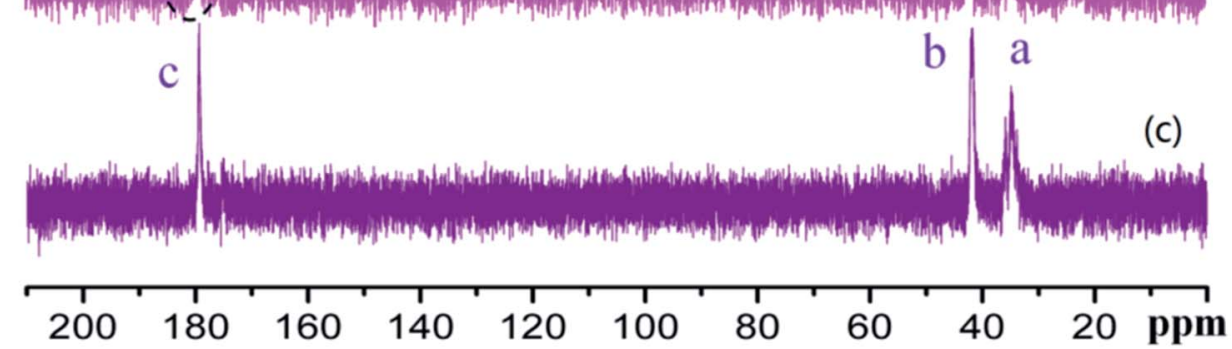

Fig. $6{ }^{13} \mathrm{C}$ NMR spectra of (a) TPAS, (a) APAS and (c) PAM.

Table 2 Relative intensity of the trials distribution calculated through the MestReNova software ${ }^{a}$

\begin{tabular}{llll}
\hline Flocculants $^{b}$ & F(AAA) (\%) & F(AAS) (\%) & F(SAS) (\%) \\
\hline APAS & 37.3 & 58.3 & 4.4 \\
TPAS & 49.7 & 45.2 & 4.1
\end{tabular}

${ }^{a}$ A, AM unit; S, SAS unit; e, SAS; f, AAS; and g, AAA. ${ }^{b}$ TPAS: copolymer of SAS and AM by UV-initiated template technique; APAS: copolymer of SAS and AM by UV-initiated copolymerization; AAA to SAS: mole fraction of the F(AAA) triad sequence to $\mathrm{F}(\mathrm{SAS})$ triad sequence.

anionic microblocks was filled with single monomer SAS rather than AM or their mixture, and therefore the number and length of the AAA trial improved greatly.

3.1.5. SEM of polymers. The SEM images of the polymers (PAM, APAS and TPAS) were displayed in Fig. 7 to investigate their amorphous morphology. It was more patent that three kind of polymers presented different surface morphology. As a homopolymer of AM, PAM showed a smooth and dense surface morphology without any holes. ${ }^{13}$ However, with the grafting of SAS on $\mathrm{AM}$, profound morphological change occurred. A porous surface morphology with a laminar structure was observed for both APAS and TPAS. Compared with AM, the anion SAS was featured by a functional chemical group of $-\mathrm{SO}_{3}-$ , thus exhibiting a in significant discrepancy in the aspect of physicochemical property. Therefore, after successful grafting monomer SAS, the surface morphologies of APAS and TPAS were more porous rather than dense. Moreover, the layout and size of the alveolate holes in the surface of APAS was regular and relative smooth, whereas those in TPAS was jumbled and disordered. It was supposed that this morphology difference resulted from the monomer distribution. Due to the anionic microblock structure, the chemical and physical properties in the microcosmos were changed significantly, and the electrostatic repulsion between the anionic microblock was extremely strong compared with that of APAS. Thus, a more ragged and hammered surface morphology was observed for TPAS, and which was consistent with the finding in the template copolymerization. ${ }^{38}$

\subsection{The association constant $\left(K_{M}\right)$ and template polymerization mechanism}

In order to deeply and systematically understand ultravioletinitiated template polymerization system, its mechanism was discussed and determined through the investigation of association constant $\left(K_{\mathrm{M}}\right)$. In this study, a $K_{\mathrm{M}}$ value of 12.01 was obtained at $n_{\mathrm{SAS}}: n_{\mathrm{AM}}=1$, which indicated that approximately three quarters of the SAS was pre-absorbed and anchored on the polymer molecular chain of template PAAC to form precursor of microblock structure under the electrostatic force, and the precursor was homopolymerized by ultraviolet-initiated radiation to breed a microblock segment. ${ }^{31}$ Thus, the UV-initiated template polymerization mechanism belonged to ZIP (I) mechanism rather than Pick-up (II) mechanism. ${ }^{35}$ Meanwhile, the ZIP (I) template polymerization mechanism vividly exhibited in Fig. 8 provided another powerful support for the formation of the anion microblock structure in TPAS. 

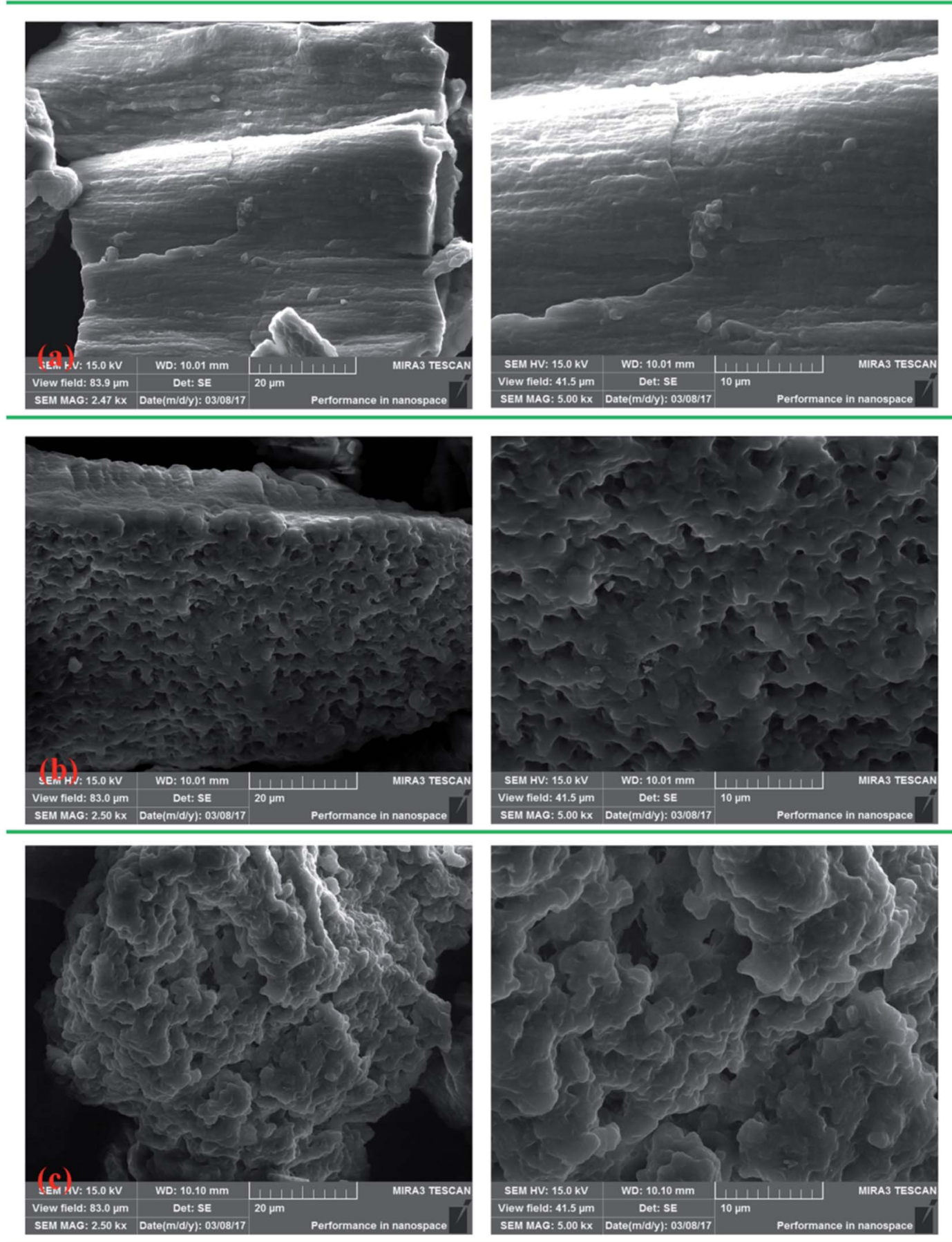

Fig. 7 The images of (a) PAM, (b) APAS and (c) TPAS

\section{Flocculation performance}

\section{1. Effect of flocculant dosage}

Due to the strong charge repulsion generated by innumerable positive charged hematite particles in the water solution, the high turbidity waste water system became more stable and resulted in troubles for solid-liquid separation. Therefore, adequate dose of flocculant with opposite charge was needed to break the stability of the hematite colloid particles. In Fig. 9, the impact of flocculant dosage on the turbidity removal rate (TR), zeta potential and floc size was investigated. Both TR and floc size first increased and then decreased, whereas zeta potential decreased in the full dosage range $\left(0.2\right.$ to $\left.1.2 \mathrm{mg} \mathrm{L}^{-1}\right)$. At the relatively low dosage range $\left(<0.8 \mathrm{mg} \mathrm{L}^{-1}\right)$, the flocculant showed a increasing efficiency in neutralizing and capturing the positive charged hematite particles with the increasing dosage. By contrast, the excessive dosage leaded to a cake effect and electrostatic repulsion which prevented the floc growth and 

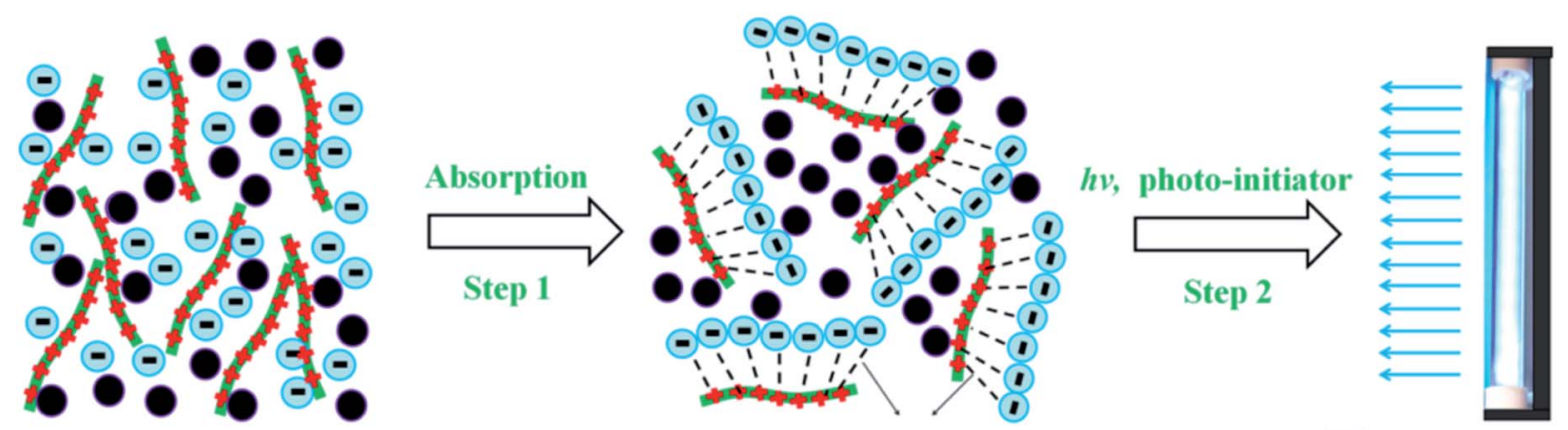

Electrostatic attraction
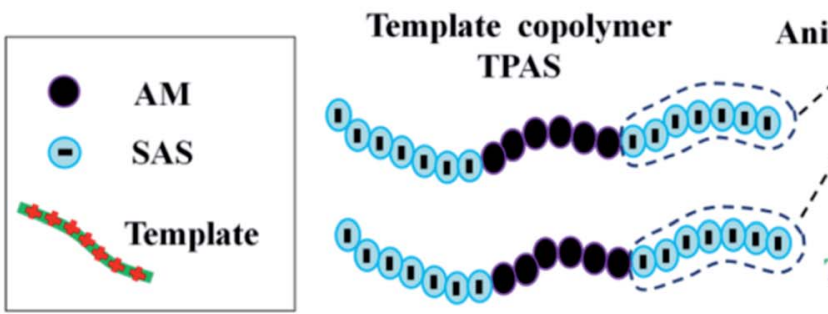

Anionic microblock

Fig. 8 The mechanism of template copolymerization.
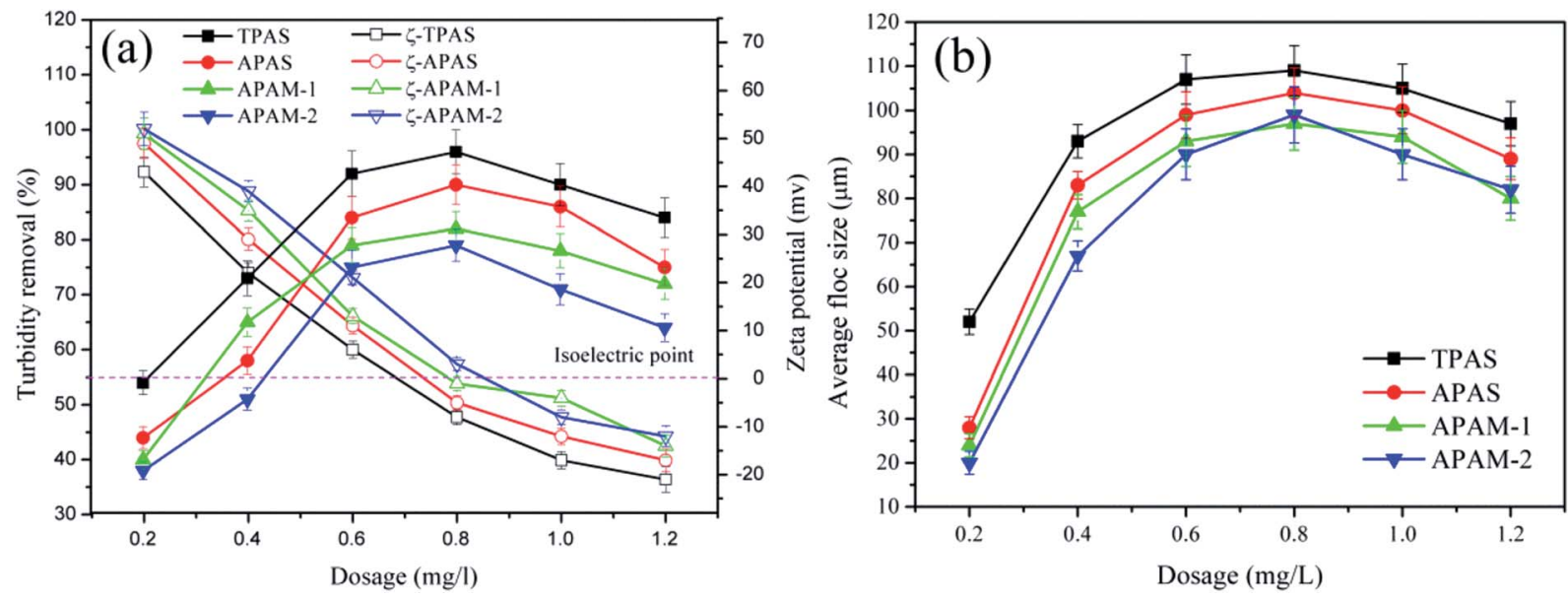

Fig. 9 Effect of the dosage on (a) turbidity removal and zeta potential, and (b) floc size.

reducing the flocculation efficiency, and thus a deterioration of the flocculation performance was observed. ${ }^{39}$ Compared with APAS, APAM-1 and APAM-2, TPAS had the highest TR and the largest floc size but the lowest zeta potential in the full range of dosage. For example, the TPAS reached the desirable flocculation performance (TR: 96.1\%; floc size: $109 \mu \mathrm{m}$; and zeta potential: $-8.3 \mathrm{mv}$ ) at the optimal dosage of $0.8 \mathrm{mg} \mathrm{L}^{-1}$. The negative charge density in the anionic microblocks was extremely enhanced, hence the charge neutralization ability of TPAS was improved. Consequently, more and more positive charged hematite particles were neutralized and destabilized completely by the anionic microblocks, and then formed large flocs under the effect of bridging. ${ }^{26}$ Previous research had also found the similar phenomenon of enhancing charge neutralization ability when the flocculant was characterized by a novel microblock structure. Moreover, the optimal dosage for each flocculant was near at that of isoelectric point, which indicated that the bridging also played an important role in the flocculation process other than charge neutralization. ${ }^{36}$

\subsection{Effect of $\mathbf{p H}$}

In addition to flocculant dosage, the effects of $\mathrm{pH}$ on turbidity removal, zeta potential, and floc size were investigated at the optimal dosage of $0.8 \mathrm{mg} \mathrm{L}^{-1}$, and the results were shown in Fig. 10. It was more clearly that the four flocculants displayed a similar flocculation variation tendency under various $\mathrm{pH}$ values ( $\mathrm{pH}$ : 1.0-11.0). A sharp and rapid increase in turbidity removal and floc size was observed at the $\mathrm{pH}$ range of 1-3, which indicated that the flocculation performance was greatly 

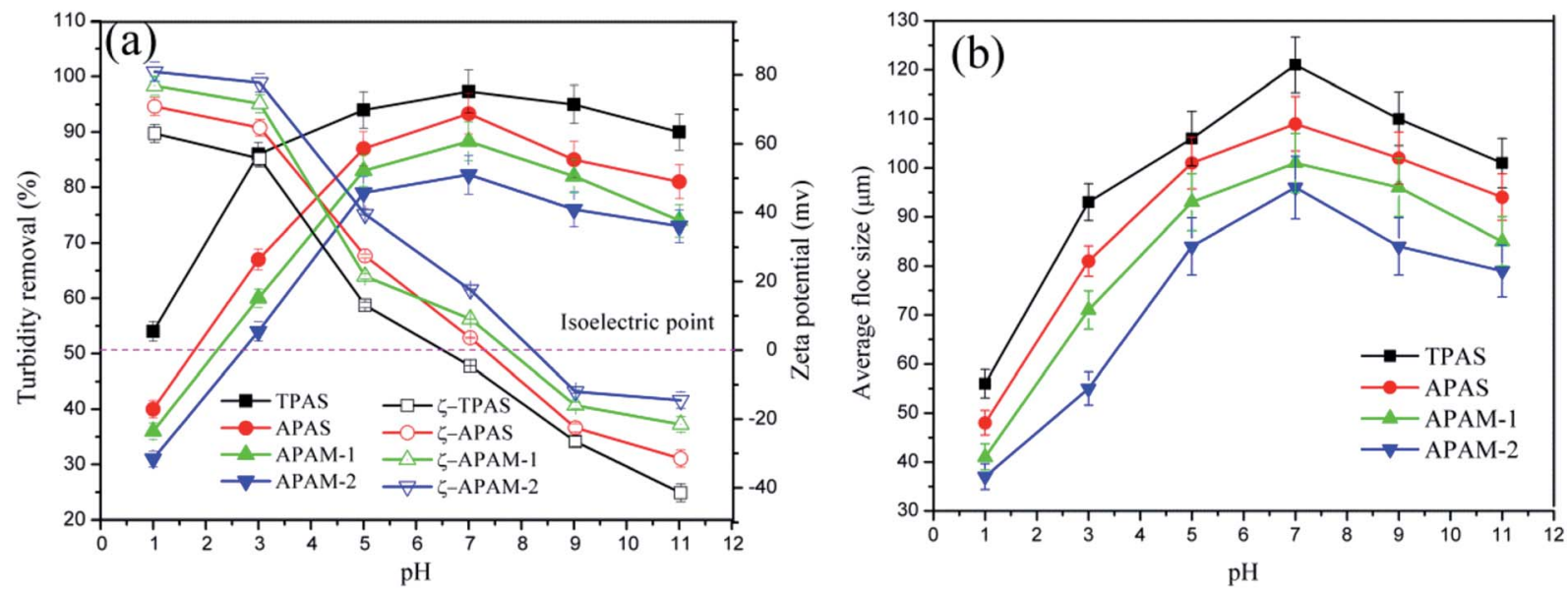

Fig. 10 Effect of the $\mathrm{pH}$ on (a) turbidity removal and zeta potential, and (b) floc size.

affected by the strong acid condition. The strong acid led to a strong charge repulsion between the hematite particles and a protonation of amino group $\left(-\mathrm{NH}_{3}{ }^{+}\right)$, hence a worse flocculation phenomenon occurred. ${ }^{40}$ The turbidity removal and floc size did not showed an exaggerated variation on alkali conditions (pH: 9.0-11.0), compared with those on acid conditions (pH: 1.0-3.0). When the $\mathrm{pH}$ condition was alkali, more and more negatively charged hydroxyl $\left(\mathrm{OH}^{-}\right)$would be attracted by the positively charged hematite particles. Theses adsorbed $\mathrm{OH}^{-}$ ions tightly wrapped hematite particles to form a protective layer which decreased the combination chance between the flocculant and hematite particles, and therefore a deteriorative flocculation performance happened. Furthermore, TPAS displayed the highest turbidity removal and the largest floc size in the full range of $\mathrm{pH}$, whereas the zeta potential was the minimum among the flocculants. Because of the anionic microblocks in the TPAS molecular chain, the strong repulsion between microblocks became especially strong and the polymer chain represented a more linear configuration, which was more capable for the reduction of molecular cross-linking occurrence and the enhancement of bridging. ${ }^{31}$ Therefore, the TPAS showed a prominent flocculation performance even under the strong acid and alkali conditions with high charge repulsion. Finally, the acceptable flocculation occurrence for TPAS was in a wider $\mathrm{pH}$ range (pH: 3-11) than those of the other three $(\mathrm{pH}$ : 5-9), which indicated that TPAS could be widely applied in the practical solid-liquid separation.

\subsection{Kinetic investigation}

The flocculation kinetics of the four flocculants were investigated at the optimal conditions (dosage $=0.8 \mathrm{mg} \mathrm{L}^{-1}, \mathrm{pH}=7$ ) to further evaluate the effect of microblock structure on the flocculation performance. The turbidity for each flocculant was recorded after the termination of the slow string (slow stirring at $50 \mathrm{rpm}$ for $15 \mathrm{~min}$ ) in each flocculation test with the same interval ( $3 \mathrm{~min})$, and the calculation of TR was shown in Fig. 11(a). Meanwhile, in order to obtain the flocculation kinetic value for each flocculant, eqn (2) was set according to the previous research, and it was shown as follows. ${ }^{41}$
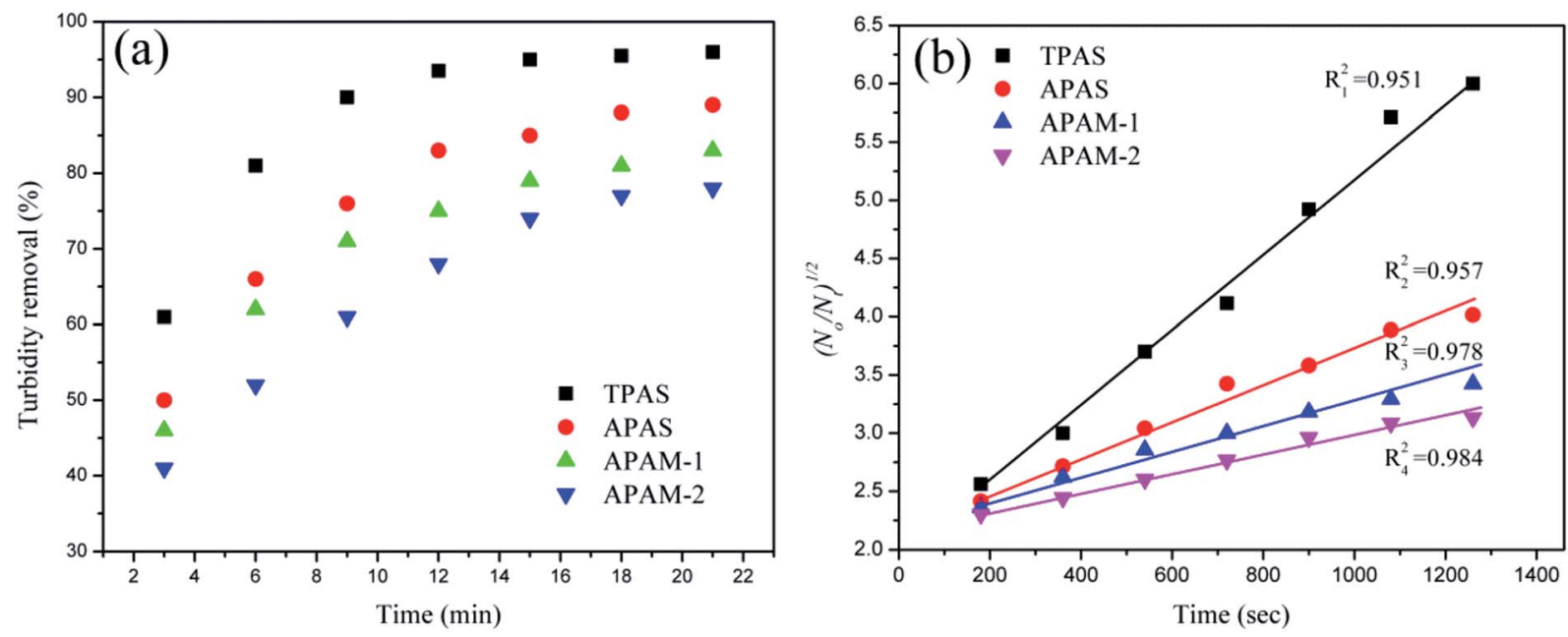

Fig. 11 The variation of turbidity removal (a) and(b) $\left(N_{0} / N_{t}\right)^{1 / 2}$ as a function of setting time for different flocculants. 
Table 3 The flocculation kinetics $\left(k N_{0}\right)$ for the four flocculants (TPAS, APAS, APAM-1 and APAM-2)

\begin{tabular}{lcc}
\hline Flocculants & Flocculation kinetics $k N_{0}\left(\times 10^{-4} \mathrm{~s}^{-1}\right)$ & $R^{2}$ \\
\hline TPAS & 33.75 & 0.951 \\
APAS & 15.83 & 0.957 \\
APAM-1 & 11.12 & 0.978 \\
APAM-2 & 7.64 & 0.984
\end{tabular}

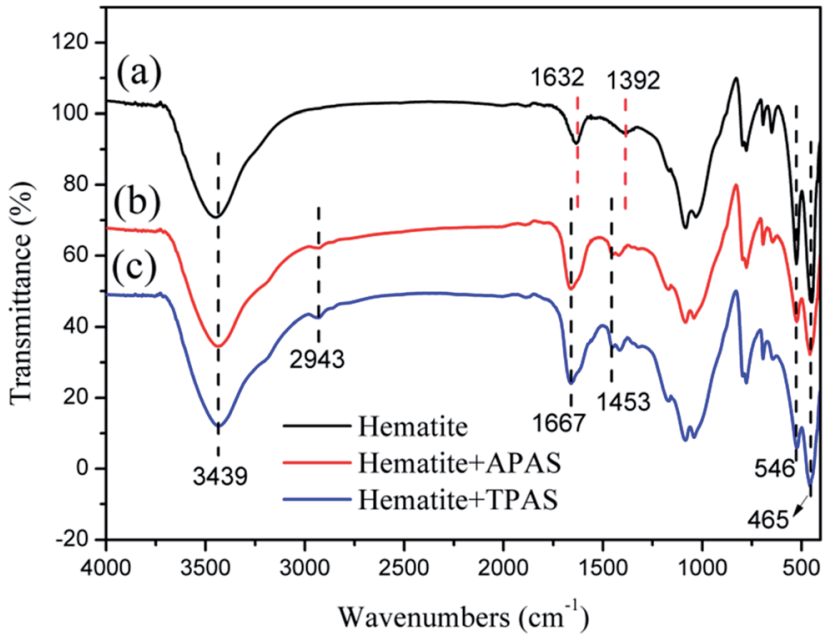

Fig. 12 FRIR spectra of hematite and flocs.

$$
\left(\frac{N_{0}}{N_{t}}\right)^{\frac{1}{2}}=1+0.5 \times k N_{0} t
$$

where $N_{0}$ was initial turbidity (172 NTU), $N_{t}$ was the turbidity as a function of time $(3,6,9,12,15,18,21 \mathrm{~min})$, and $k$ was the kinetic constant in the flocculation system. The specific kinetic value of each flocculant was illustrated in Table 3 .

Based on the above results, it was found that the four flocculants displayed a similar TR trend of increasing gradually to a plateau shown in Fig. 11(a), whereas the TPAS increased rapidly during the first of $9 \mathrm{~min}$. Moreover, in Fig. 11(b), the slope of the simulated curve for TPAS $\left(k N_{0}=33.75 \times 10^{-4} \mathrm{~s}^{-1}\right)$ was the largest among the flocculants, which manifested that the TPAS flocculated the positive charged hematite particles so efficiently and the RT was improved so significantly. The anionic microblocks attracted and neutralized the positive charged particles quickly through strong charge neutralization, and thus the hematite particles lost their stabilization. Subsequently, the inactive hematite particles were captured and anchored by the molecular chain of TPAS to form a large and compact floc structure shown in ESI Fig. S1. $\uparrow$ Thus, these flocs had a fast sedimentation velocity and the turbidity declined sharply. On the contrary, the random distribution of anionic monomer in APAS, APAM-1 and APAM-2 extremely weakened the charged neutralization ability and a part of hematite particles could not be neutralized completely. As a result, the generated flocs shown in ESI Fig. S2 $\uparrow$ was small and loose, and thereby APAS, APAM-1 and APAM-2 displayed a higher turbidity and a lower kinetic constant, compared with those of TPAS. Moreover, the TPAS also displayed a desirable flocculation efficiency compared with the previous results of the published works. $^{42,43}$

\subsection{FTIR analysis of the flocs}

As reported previously, the FTIR spectra of the generated flocs were measured to investigated the interaction between the flocculant and hematite particles. ${ }^{44}$ In Fig. 12, before flocculation, the hematite particles showed the following adsorption

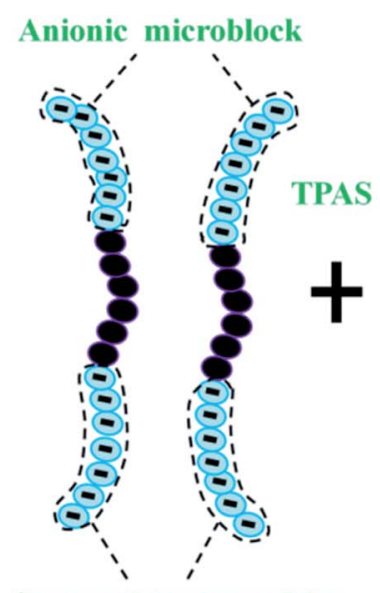

Strong charge repulsion
SAS

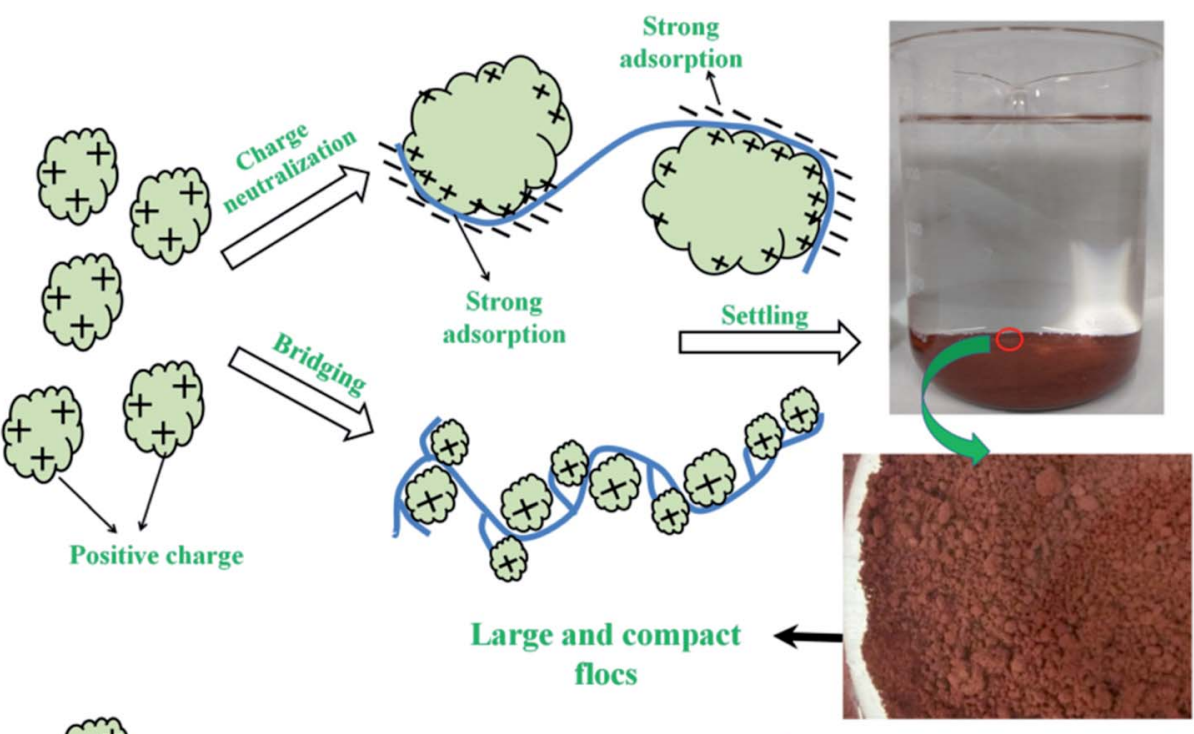

Hematite particle
Template copolymer

Fig. 13 Possible flocculation mechanism of the TPAS. 
peaks. The adsorption peaks at $3439 \mathrm{~cm}$ and $1632 \mathrm{~cm}$ were attributed to the water of hydration; ${ }^{45}$ The bending frequency of surface hydroxyl group was observed at $1392 \mathrm{~cm}^{; 6}$ And the adsorption peaks at $546 \mathrm{~cm}$ and $465 \mathrm{~cm}$ were assigned to $\mathrm{Fe}-\mathrm{O}$ vibrational mode. ${ }^{47}$ After flocculation, these peaks all observed in hematite + APAS and hematite + TPAS. Meanwhile, the characteristic peaks of both APAS and TPAS were observed at $2943 \mathrm{~cm}\left(-\mathrm{CH}_{3}\right), 1167 \mathrm{~cm}(\mathrm{C}=\mathrm{O})$ and $1453 \mathrm{~cm}\left(-\mathrm{CH}_{2}-\mathrm{N}^{+}\right)$in hematite + APAS and hematite + TPAS. Based on the above results. It indicated that hematite particles were flocculated by APAS and TPAS and separated from the liquid. Besides, in addition to the original chemical bonds of hematite, APAS and TPAS, new chemical bonds were not observed in the FTIR spectra of hematite + APAS and hematite + TPAS, thus indicating that the flocculation occurrence was caused by electrostatic interaction and bridging rather than chemical reaction between hematite and the flocculant. ${ }^{48}$

\subsection{Flocculation mechanism}

The mechanism involved in the flocculation process was discussed and summarized, and it was illustrated in Fig. 13. Two dominant flocculation mechanisms, namely, charge neutralization and bridging, contributed much to the prominent flocculation performance of TPAS such as high TR, large and compact floc size, and high kinetic constant. The charge density and intensity was extremely enhanced by the anionic microblocks of TPAS, and thus the charge neutralization ability was greatly improved. However, the situation for the other three flocculants was just opposite, and the disorder and random distribution of anionic monomers caused a discount for their charge neutralization ability. When the TPAS was added, the positive charge particles were absorbed on the surface of the polymer and tightly combined with the polymer chain of TPAS trough charge neutralization rather than chemical bond. Meanwhile, the anionic microblocks of TPAS was more favorable for the improvement of the bridging ability. The strong charge repulsion generated by the anionic microblocks contributed much to the stretch and extension of TPAS polymer chain, and therefore more active position would be exposed to capture the particles to aggregate and form large and compact flocs. At last, the flocs conditioned by TPAS sank fast to bottom, which was more facile for the solid-liquid separation.

\section{Conclusions}

A new anionic flocculant TPAS with the microblock structure was successfully synthesized through UV-initiated polymerization. The structure properties of TPAS was characterized by the FT-IR, ${ }^{1} \mathrm{H}\left({ }^{13} \mathrm{C}\right) \mathrm{NMR}$, SEM and TG/DSC, and the results indicated that the formation of the microblock structure. Meanwhile, the template polymerization mechanism was demonstrate to be I (ZIP) mechanism through a high $K_{\mathrm{M}}$ value $\left(K_{\mathrm{M}}: 12.01\right)$, and which also provided another proof for the generation of the microblock structure. The flocculation test for the removal of hematite particles indicated that TPAS with the microblock structure had an excellent flocculation performance through the enhancement of charge neutralization and bridging ability. A stable and powerful bond but not chemical bond was generated between the anionic microblock structure and hematite particles under the effect of charge neutralization and bridging. In this case, the flocs flocculated by TPAS were compact and large. Meanwhile, the reaction rate and turbidity remove rate was also the fast and highest, respectively, for TPAS among the flocculants.

\section{Acknowledgements}

The authors are grateful for the financial support provided by the National Natural Science Foundation of China (Project No. 21677020 and 21477010).

\section{References}

1 C. J. Chen, B. Chen, Z. Li and Z. Q. Wang, Important role of magma mixing in generating the Mesozoic monzodioriticgranodioritic intrusions related to $\mathrm{Cu}$ mineralization, Tongling, East China: Evidence from petrological and in situ Sr-Hf isotopic data, Lithos, 2016, 248, 80-93.

2 L. Chen, Z. D. Hao, T. Z. Yang, H. Xiao, W. F. Liu, D. C. Zhang, S. Bin and W. D. Bin, An Efficient Technology for Smelting Low Grade Bismuth-Lead Concentrate: Oxygen-Rich Side BlowProcess, JOM, 2015, 67, 1997-2004.

3 A. Tremel, T. Haselsteiner, C. Kunze and H. Spliethoff, Experimental investigation of high temperature and high pressure coal gasification, Appl. Energy, 2012, 92, 279-285.

4 R. D. Li, W. W. Zhao, Y. L. Li, W. Y. Wang and X. Zhu, Heavy metal removal and speciation transformation through the calcination treatment of phosphorus-enriched sewage sludge ash, J. Hazard. Mater., 2015, 28, 423-431.

5 Y. X. Yu, G. Cheng, L. Q. Ma, G. Huang, L. Wu and H. X. Xu, Effect of agitation on the interaction of coal and kaolinite in flotation, Powder Technol., 2017, 313, 122-128.

6 T. Nasim and A. Bandyopadhyay, Introducing different poly(vinyl alcohol)s as new flocculant for kaolinated waste water, Sep. Purif. Technol., 2012, 88, 87-94.

7 M. S. Silverstein, Emulsion-templated porous polymers: A retrospective perspective, Polymer, 2014, 55, 304-320.

8 C. Y. Hua, S. L. Lo, C. L. Chang, F. L. Chen, Y. D. Wu and J. L. Mad, Treatment of highly turbid water using chitosan and aluminum salts, Sep. Purif. Technol., 2013, 104, 322-326.

9 M. S. Nasser, Characterization of floc size and effective floc density of industrial papermaking suspensions, Sep. Purif. Technol., 2014, 122, 495-505.

10 L. Pérez, J. L. Salgueiro, R. Maceiras, Á. Cancela and Á. Sánchez, Study of influence of $\mathrm{pH}$ and salinity on combined flocculation of Chaetoceros gracilis microalgae, Chem. Eng. J., 2016, 286, 106-113.

11 T. J. Lee, S. J. Hong, J. Y. Park and H. J. Kim, Effects of Anionic Polyacrylamide on Carbonation for the Crystallization of Precipitated Calcium Carbonate, Cryst. Growth Des., 2015, 15, 1652-1657. 
12 K. R. Desaia and Z. V. P. Murthya, Removal of silver from aqueous solutions by complexation - ultrafiltration using anionic polyacrylamide, Chem. Eng. J., 2012, 185, 187-192.

13 H. L. Zheng, J. Y. Ma, C. J. Zhu, Z. Zhang, L. W. Liu, Y. J. Sun and X. Tang, Synthesis of anion polyacrylamide under UV initiation and its application in removing dioctyl phthalate from water through flocculation process, Sep. Purif. Technol., 2014, 123, 35-44.

14 B. Boltoa and J. Gregory, Organic polyelectrolytes in water treatment, Water Res., 2007, 41, 2301-2324.

15 M. Hjorth and B. U. Jørgensen, Polymer flocculation mechanism in animal slurry established by charge neutralization, Water Res., 2012, 46, 1045-1051.

16 X. S. Yi, W. X. Shi, S. L. Yu, X. H. Li, N. Sun and C. He, Factorial design applied to flux decline of anionic polyacrylamide removal from water by modified polyvinylidene fluoride ultrafiltration membranes, Desalination, 2011, 274, 7-12.

17 J. L. Kerr, J. S. Lumsden, S. K. Russell, E. J. Jasinska and G. G. Goss, Effects of anionic polyacrylamide products on gill histopathology in juvenile rainbow trout (Oncorhynchus mykiss), Environ. Toxicol. Chem., 2014, 33, 1552-1562.

18 C. L. Zhao, H. L. Zheng, L. Feng, Y. L. Wang, Y. Z. Liu, B. Z. Liu and B. Z. Djibrine, Improvement of Sludge Dewaterability by Ultrasound-Initiated Cationic Polyacrylamide with Microblock Structure: The Role of Surface-Active Monomers, Materials, 2017, 10, 282.

19 L. Feng, H. L. Zheng, Y. L. Wang, S. X. Zhang and B. C. Xu, Ultrasonic-template technology inducing and regulating cationic microblocks in CPAM: characterization, mechanism and sludge flocculation performance, $R S C$ Adv., 2017, 7, 23444-23456.

20 W. C. Chai, Y. W. Zhang and Y. F. Hou, Well-defined cationic polyacrylamides with dot-charges: synthesis via an aqueous living RAFT polymerization, characterization, and intrinsic viscosity, Polym. Chem., 2013, 4, 1006-1013.

21 T. T. Albrecht, J. Schotter, G. A. Kästle, N. Emley, T. Shibauchi, L. Krusin-Elbaum, K. Guarini, C. T. Black, M. T. Tuominen and T. P. Russell, Ultrahigh-Density Nanowire Arrays Grown in Self- Assembled Diblock Copolymer Templates, Science, 2000, 290, 2126-2129.

$22 \mathrm{M}$. Q. Li and C. K. Ober, Block copolymer patterns and templates, Mater Today, 2006, 9, 30-39.

23 Q. L. Zhang, T. Xu, D. Butterfield, M. J. Misner, D. Y. Ryu, T. Emrick and T. P. Russell, Controlled Placement of CdSe Nanoparticles in Diblock Copolymer Templates by Electrophoretic Deposition, Nano Lett., 2005, 5, 2.

24 D. Sprouse, Y. M. Jiang, J. E. Laaser, T. P. Lodge and T. M. Reineke, Tuning Cationic Block Copolymer Micelle Size by $\mathrm{pH}$ and Ionic Strength, Biomacromolecules, 2016, 17, 2849-2859.

25 Y. X. Zhang, F. P. Wu, M. Z. Li and E. J. Wang, Novel Approach to Synthesizing Hydrophobically Associating Copolymer Using Template Copolymerization: The Synthesis and Behaviors of Acrylamide and 4-
(ö-Propenoyloxyethoxy) Benzoic Acid Copolymer, J. Phys. Chem. B, 2005, 109, 22250-22255.

26 H. L. Zheng, Y. J. Sun, C. J. Zhu, J. S. Guo, C. Zhao, Y. Liao and Q. Q. Guan, UV-initiated polymerization of hydrophobically associating cationic flocculants: Synthesis, characterization, and dewatering properties, Chem. Eng. J., 2013, 234, 318-326.

27 T. Lou, X. J. Wang, G. J. Song and G. P. Cui, Synthesis and flocculation performance of a chitosan-acrylamide-fulvic acid ternary copolymer, Carbohydr. Polym., 2017, 170, 182189.

28 X. Li, H. L. Zheng, Y. L. Wang, Y. J. Sun, B. C. Xu and C. L. Zhao, Fabricating an enhanced sterilization chitosanbased flocculants: Synthesis, characterization, evaluation of sterilization and flocculation, Chem. Eng. J., 2017, 319, 119-130.

29 Z. Yang, H. Yang, Z. W. Jiang, T. Cai, H. J. Li, H. B. Li, A. Li and R. S. Cheng, Flocculation of both anionic and cationic dyes in aqueous solutions by the amphoteric grafting flocculant carboxymethyl chitosan-graft-polyacrylamide, $J$. Hazard. Mater., 2013, 254, 36-45.

30 S. H. Lv, Q. F. Zhou, Y. Y. Cui, W. Q. Yang and Y. Li, Synthesis of graphene oxide-methacrylicacid-sodium allyl sulfonate copolymer and its tanning properties, Arabian J. Chem., 2015, 6, 1-10.

31 X. Li, H. L. Zheng, B. Y. Gao, Y. J. Sun, B. Z. Liu and C. L. Zhao, UV-initiated template copolymerization of AM and MAPTAC: Microblock structure, copolymerization mechanism, and flocculation performance, Chemosphere, 2017, 167, 71-81.

32 Y. X. Zhao, B. Y. Gao, H. Y. Rong, H. K. Shon, J. H. Kim, Q. Y. Yue and Y. Wang, The impacts of coagulant aidpolydimethyldiallylammonium chloride on coagulation performances and floc characteristics in humic acid-kaolin synthetic water treatment with titanium tetrachloride, Chem. Eng. J., 2011, 173, 376-384.

33 K. J. Yao and G. W. Zhuo, Synthesis and Rheological Properties in Aqueous Solution of Poly(Acrylamide-coSodium Allylsulfonate), J. Appl. Polym. Sci., 1992, 44, 1-7.

34 Y. Liao, H. L. Zheng, L. Qian, Y. j. Sun, L. Dai and W. W. Xue, UV-Initiated Polymerization of Hydrophobically Associating Cationic Polyacrylamide Modified by a Surface-Active Monomer: A Comparative Study of Synthesis, Characterization, and Sludge Dewatering Performance, Ind. Eng. Chem. Res., 2014, 53, 11193-11203.

35 L. Feng, H. L. Zheng, B. Y. Gao, C. L. Zhao, S. X. Zhang and N. Chen, Enhancement of textile-dyeing sludge dewaterability using a novel cationic polyacrylamide: role of cationic block structures, RSC Adv., 2017, 7, 11626-11635.

36 W. Chen, H. L. Zheng, Q. Q. Guan, H. K. Teng, C. L. Zhao and C. Zhao, Fabricating a Flocculant with Controllable Cationic Microblock Structure: Characterization and Sludge Conditioning Behavior Evaluation, Ind. Eng. Chem. Res., 2016, 55, 2802-2902.

37 H. L. Zheng, L. Feng, B. Y. Gao, Y. H. Zhou, S. X. Zhan and B. C. Xu, Effect of the Cationic Block Structure on the 
Characteristics of Sludge Flocs Formed by Charge Neutralization and Patching, Materials, 2017, 10, 478.

38 Q. Q. Guan, H. L. Zheng, J. Zhai, C. Zhao, X. K. Zheng, X. M. Tang, W. Chen and Y. J. Sun, Effect of Template on Structure and Properties of Cationic Polyacrylamide: Characterization and Mechanism, Ind. Eng. Chem. Res., 2014, 53, 5624-5635.

39 J. Y. Ma, K. Fu, L. Y. Jiang, L. Ding, Q. Q. Guan, S. H. Zhang, H. W. Zhang, J. Shi and X. Fu, Flocculation performance of cationic polyacrylamide with high cationic degree in humic acid synthetic water treatment and effect of kaolin particles, Sep. Purif. Technol., 2017, 181, 201-212.

40 H. L. Zheng, Y. J. Sun, J. S. Guo, F. T. Li, W. Fan, Y. Liao and Q. Q. Guan, Characterization and Evaluation of Dewatering Properties of PADB, a Highly Efficient Cationic Flocculant, Ind. Eng. Chem. Res., 2014, 53, 2572-2582.

41 B. S. Kaith, R. Jindall and R. Sharma, Study of ionic charge dependent salt resistant swelling behavior and removal of colloidal particles using reduced gum rosinpoly(acrylamide)-based green flocculant, Iran. Polym. J., 2016, 25, 349-362.

42 J. Y. Ma, J. Shi, H. C. Ding, G. C. Zhu, K. Fu and X. Fu, Synthesis of cationic polyacrylamide by low-pressure UV initiation for turbidity water flocculation, Chem. Eng. J., 2017, 312, 20-29.

43 R. Suresh, R. Prabu, A. Vijayaraj, K. Giribabu, A. Stephen and V. Narayanan, Facile synthesis of cobalt doped hematite nanospheres: Magnetic and their electrochemical sensing properties, Mater. Chem. Phys., 2012, 134, 590-596.

44 R. H. Li, H. B. Zhang, X. Q. Hu, W. W. Gan and Q. P. Li, An efficiently sustainable dextran-based flocculant: Synthesis, characterization and flocculation, Chemosphere, 2016, 159, 342-350.

45 G. Muthuraman and S. Sasikala, Removal of turbidity from drinking water using natural coagulants, J. Ind. Eng. Chem., 2014, 20, 1727-1731.

46 G. K. Pradhan and K. M. Parida, Fabrication, Growth Mechanism, and Characterization of $\alpha-\mathrm{Fe}_{2} \mathrm{O}_{3}$ Nanorods, ACS Appl. Mater. Interfaces, 2011, 3, 317-323.

47 A. Rufus, N. Sreeju and D. Philip, Synthesis of biogenic hematite $\left(\mathrm{a}-\mathrm{Fe}_{2} \mathrm{O}_{3}\right)$ nanoparticles for antibacterial and nanofluid applications, RSC Adv., 2016, 6, 94206-94217.

48 J. Y. Ma, K. Fu, X. Fu, Q. Q. Guan, L. Ding, J. Shi, G. C. Zhu, X. X. Zhang, S. H. Zhang and L. Y. Jiang, Flocculation properties and kinetic investigation of polyacrylamide with different cationic monomer content for high turbid water purification, Sep. Purif. Technol., 2017, 182, 134-143. 